\title{
Влияние цифровой экономики на бизнес
}

В.Д. МАРКОВА, доктор экономических наук,

Институт экономики и организации промышленного производства СО РАН, Новосибирск

В статье представлена авторская позиция относительно направлений влияния цифровой экономики на деятельность компаний, основанная на анализе зарубежных исследований и российской практике цифровой трансформации. Акцент сделан на новые инструменты и принципы управления бизнесом, которые определяют конкурентоспособность компаний в цифровой экономике и ведут к формированию новой производственной философии. На примерах российских компаний показано, что цифровая трансформация пока охватывает лишь отдельные процессы и объекты бизнеса.

Ключевые слова: цифровая трансформация бизнеса, платформенные бизнесмодели, модель «продукт как услуга», новая производственная философия

Цифровые технологии радикально меняют отрасли и рынки, оказывая разностороннее влияние на деятельность компаний. Однако менеджеры и специалисты пока слабо осознают возможности и угрозы, связанные с цифровой экономикой. Более того, зачастую цифровая трансформация воспринимается как новый этап автоматизации бизнеса, хотя исследования показывают, что цифровые и связанные с ними технологии, такие как когнитивные и искусственный интеллект, технологии дополненной и виртуальной реальности, аддитивные и многие другие, формируют новые реалии бизнеса. Пока в полной мере эти реалии не понятны, поэтому в англоязычной литературе для них приняты различные названия: «Цифровая экономика» (Digital Economy), «Платформенная экономика» (Platform Economics), «Экономика алгоритмов» (Algorithm Economy), «Экономика экосистем» (Economics of Ecosystems). Неустоявшийся понятийный аппарат в сочетании с «модой» на цифровую экономику приводят, с одной стороны, к широкому и зачастую неоправданному использованию этого термина даже в научной литературе, а с другой - к тому, что реальные возможности этого мирового тренда нередко упускаются, а его потенциал недоиспользуется. 


\section{Цифровая экономика}

Развитие цифровой экономики, которую в самом общем виде можно представить как экономику, основанную на широком использовании цифровых технологий, обусловлено масштабными и радикальными преобразованиями всех сторон жизнедеятельности человека под воздействием цифровых технологий. Последние позволяют передавать, хранить, обрабатывать и искать разнообразные данные с обеспечением высоких показателей качества, скорости, простоты и надежности этих процессов.

Собственно драйверами цифровой трансформации (цифровизации) стали:

- сенсорные технологии и технологии радиочастотной идентификации объектов, на базе которых созданы разнообразные цифровые устройства (датчики), позволяющие генерировать данные в непрерывном режиме. Эти устройства в принципе могут быть установлены на любом объекте - оборудовании, зданиях, сооружениях, животных, растениях, также их носит человек;

- глобальная система мобильных коммуникаций, включающая спутниковую, мобильную связь, Интернет и локальные сети передачи данных;

- облачные / туманные технологии, обеспечивающие хранение больших массивов информации, а затем и возможность работы с ними непосредственно на удаленных серверах;

- высокопроизводительные компьютеры, которые предоставили возможность работать с так называемыми «большими данными» (Big Data).

Трансформация традиционной индустрии в цифровую началась с середины 1990-х годов - в мире музыки, фото- и видеозаписи. В период 2006-2007 гг. появляется «Интернет вещей» (Internet of Thing, IoT), то есть количество подсоединенных к Интернету объектов превысило количество людей, использующих его. Затем наступило время цифрового маркетинга и цифрового телевидения. Постепенно с нарастающей скоростью цифровая трансформация охватывает различные отрасли - торговлю, образование, финансы, здравоохранение, ЖКХ, промышленность, транспорт и др.

Важным периодом в развитии процессов цифровой трансформации были 2004-2007 гг, когда появилась социальная сеть Facebook как канал коммуникаций и обмена информацией (2004 г.), затем канал YouTube, позволяющий выкладывать 
и смотреть видеоматериалы (2005 г.). Платформа Amazon Web Service (AWS) упростила и удешевила процесс создания онлайнкомпаний, в частности интернет-магазинов (2006 г.), а смартфон iPhone и операционная система Android от Google в 2007 г. буквально взорвали рынок, запустив процесс развития рынка мобильных приложений. Собственно с этого периода и началось стремительное развитие цифровой экономики.

Широкому распространению цифровых технологий способствует быстрое снижение цен на цифровые устройства при столь же быстром расширении их функционала при высокой степени надежности (они могут годами работать без сервисного обслуживания).

Разнообразие и количество цифровых устройств в сфере бизнеса и в обыденной жизни непрерывно увеличиваются. Помимо всем привычных банкоматов, появились разнообразные вендинговые аппараты, которые продают напитки и снеки, готовят кофе и чай, делают ксерокопии и фотографии, принимают платежи и др. К ноутбукам, планшетным компьютерам и смартфонам добавляются цифровые телевизоры, видеокамеры, браслеты для фитнеса, «умные» часы, разные носимые устройства и датчики, которые можно устанавливать на различных объектах - от автомобилей и оборудования до растений, животных и людей. Причем все эти устройства часто работают круглосуточно в режиме 24/7. По сути, можно говорить о наступлении века мобильности и «больших данных».

Таким образом, можно дать следующее определение: цифровая экономика - это «новый этап развития экономики, в основе которого лежит интеграция физических и цифровых (виртуальных) объектов в сфере производства и потребления, в экономике и обществе» [Маркова, 2018. С. 10]. Эта интеграция ведет к расширению сетевых коммуникаций, скоростному соединению людей, процессов, данных и предметов, позволяя создавать новые ценности, расширяя горизонты человеческого мышления. О такой интеграции говорят многие авторы, в частности С. Грингард отмечает, что у Интернета вещей (IоT) и Индустрии 4.0 есть общая цель - объединение физического и виртуального миров, стирание границ между ними [Грингард, 2016. С. 70]. М. Иансати и К. Лакхани, изучив цифровую трансформацию в нескольких десятках отраслей и компаний, делают вывод, что суть ее в возможности взаимодействия и перегруппировки, когда «все операции и каждое взаимодействие представляют в цифровом 
виде, данные генерируются и анализируются по-новому, а между прежде разрозненными объектами, людьми и видами деятельности устанавливается связь» [Иансати, 2014. С. 75].

Исходя из этого, мы рассматриваем цифровую трансформацию бизнеса (цифровизацию) как процесс превращения традиционной организации в цифровую компанию, в деятельности которой присутствуют как материальные, так и цифровые объекты. Цифровыми объектами являются цифровой двойник технически сложного изделия, интернет-магазин, онлайн-банк, сайт компании, робот/бот как цифровая модель работы колл-центра, причем этот перечень непрерывно расширяется. Иллюстрация различий между автоматизацией и цифровизацией приведена в таблице 1.

\section{Таблица 1. Автоматизация vs цифровизация}

\begin{tabular}{|l|l|}
\multicolumn{1}{|c|}{ Автоматизация: } & \multicolumn{1}{c|}{\begin{tabular}{c}
\multicolumn{1}{|c|}{ Цифровизация: } \\
челехновек помогает IT-технологиям помогают человеку
\end{tabular}} \\
\hline Станки с ЧПу & 3D-принтер, 3D-технологии \\
\hline Навигатор в автомобиле & Беспилотный автомобиль \\
\hline $\begin{array}{l}\text { Диспетчер такси, работа которого автомати- } \\
\text { зирована }\end{array}$ & Платформа Uber \\
\hline Внутренние ERP-системы предприятий & $\begin{array}{l}\text { Система партнерства на основе цифровой модели } \\
\text { изделия (самолета Boeing) }\end{array}$ \\
\hline
\end{tabular}

Источник: составлено автором.

В целом мгновенные сетевые коммуникации и «большие данные» как важные составляющие процессов цифровой трансформации оказывают радикальное влияние на экономику и бизнес (Купер, 2017). Однако на данном этапе развития цифровой экономики в России это влияние наиболее наглядно проявляется в следующем:

- формируются новые модели бизнеса, которые ведут к трансформации отраслей и рынков и становятся важным фактором конкурентоспособности компаний;

- постепенно формируется новая производственная философия.

Можно выделить два аспекта применительно к новым моделям бизнеса: это развитие платформенных моделей бизнеса, a также расширение практики применения модели поставок оборудования как услуги (модель PaaS).

\section{Платформенные модели бизнеса}

Специфической чертой цифровой экономики с позиций организации и управления бизнесом является бурное развитие 
цифровых платформ, которые, по мнению многих исследователей [Eisenmann, 2008; Zhu and Iansiti, 2012; Muegge, 2013; Паркер и др., 2017], становятся «строительными блоками» цифровой экономики. В исследованиях 2015 г. известная консалтинговая компания Accenture выделила тренд, который назвала «(Р)эволюция платформ» (Platform (R)evolution). По мнению компании, появление новых цифровых платформ обещает не меньшую революцию, чем создание фабрик более двух веков назад. Поэтому Accenture говорит о платформенной экономике как об одном из важнейших направлений развития цифровых технологий ${ }^{1}$.

В мир бизнеса термин пришел из инженерной сферы, где существует понятие платформы продукта (автомобиля, смартфона) и сферы программного обеспечения (программные платформы Windows и др.), однако применительно к бизнесу вряд ли возможно дать единственно верное определение платформы.

По мнению некоторых экспертов [Muegge, 2013], цифровая платформа как модель бизнеса - это совокупность частично или полностью открытых технологий и активов, которые могут быть использованы независимыми компаниями и частными лицами для разработки дополняющих технологий, продуктов и сервисов. Это целостная структура, состоящая из множества компонентов и общих правил (стандартов) функционирования, объединяющая людей, компании и ресурсы с целью создания и распространения ценностей для потребителей. Соответственно важными составляющими платформенной модели бизнеса являются технологии, коммуникации и система управления.

Предоставляя другим компаниям возможность использования технологий платформы, ее владелец выходит за границы своей компании, формируя экосистему бизнеса как динамично развивающегося сообщества разнообразных субъектов (акторов), создающих новые ценности в процессе как взаимодействия, так и конкуренции. Это можно показать на примере российской компании $1 \mathrm{C}$, успешное развитие которой обеспечивают экспертные знания и отраслевая специализация сотрудников более 3 тыс. организаций из России и стран СНГ, сотрудничающих с компанией на условиях франчайзинга. Разветвленная партнерская сеть, сформированная на основе цифровой платформы $1 \mathrm{C}$, включает более

\footnotetext{
${ }^{1}$ URL: http://www.ludidela.ru/articles/1073509/ (дата обращения: 10.03.2018).
} 
10000 постоянных партнеров в 600 городах и 25 странах. Платформенная модель бизнеса позволила компании 1С занять второе место на российском рынке информационных систем управления компаниями, уступив только мировому лидеру компании SAP.

Некоторые примеры платформ в зарубежной и российской экономике приведены в таблице 2 .

\section{Таблица 2. Примеры платформенных компаний}

\begin{tabular}{|c|c|}
\hline Сфера бизнеса & Платформенные компании \\
\hline Розничная торговля & $\begin{array}{l}\text { Amazon, Alibaba, OZON.Ru, «Aгро24», «Яндекс.Маркет», «Мир } \\
\text { торговли», Lamoda, KupiVip.Ru, Goods.Ru, Avito, ЮЛА, «Из рук } \\
\text { в руки» и др. }\end{array}$ \\
\hline Аренда жилья и недвижимость & Airbnb, ЦИАН.PУ, N1.RU \\
\hline Поездки и путешествия & $\begin{array}{l}\text { Uber, BlaBlacar, Zipcar, «Яндекс.Taкси», Booking.com, TripAdvisor, } \\
\text { Ozon.travel, «Яндекс.Билеты», Aviasales.ru и др. }\end{array}$ \\
\hline Финансовая и банковская сфера & $\begin{array}{l}\text { Платежные системы (МИР, Viza, AliPay и др.), QIWI, «Яндекс.День- } \\
\text { ги», ТинькоффБанк, «Вдолг.py», Kickstarter, Сбербанк-онлайн идр. }\end{array}$ \\
\hline $\begin{array}{l}\text { Коммуникации, связь, социальные } \\
\text { сети и медиасфера }\end{array}$ & $\begin{array}{l}\text { YouTube, Facebook, Instagram, Twitter, Snapchat, «ВКонтакте», } \\
\text { Mail.ru, «Одноклассники», Википедия и др. }\end{array}$ \\
\hline Сельское хозяйство & OnFarm \\
\hline Здравоохранение & «Аптека.ру», Phillips \\
\hline Образование & Coursera, Moodle, «Открытое образование» и др. \\
\hline Автоматизация управления & Компания 1C, SAP, «Галактика» \\
\hline $\begin{array}{l}\text { Справочные и картографические } \\
\text { системы поиска }\end{array}$ & Google, Яндекс, 2 гис \\
\hline Промышленность & Apple, Boing \\
\hline
\end{tabular}

Конкурентным преимуществом платформ является сотрудничество, позволяющее совместно использовать ресурсы участников (принцип шеринга), быстро развиваться за счет сокращения транзакционных издержек, облегчения доступа к клиентам и вывода новинок на рынок, формировать новые технологии и инновации, а также генерировать «большие данные» для последующей аналитики и монетизации. Широкому распространению цифровых платформ способствовало то, что они помогают найти более дешевые товары и услуги (проблема расточительности), содействуют совместному использованию ресурсов, решают проблему избыточности участников в цепи поставок, снимают ограничения доступа для потребителей и поставщиков (Uber, Coursera) и т.д. Заметим, что в 2016 г. 4,2\% взрослого населения США получали доход, используя платформы Uber, Airbnb, BlaBlacar и другие. 
Феномен стремительного взлета и широкого распространения цифровых платформ как новых моделей бизнеса ставит множество вопросов перед исследователями и практиками. Эти вопросы связаны с уточнением понятийного аппарата и классификацией платформ, с выявлением особенностей их функционирования в разных сферах и обобщением лучших практик платформенных компаний с целью выработки методических рекомендаций по формированию и управлению платформами.

Признанными лидерами в развитии платформенного бизнеса и его исследованиях являются США. Так, Ф. Саймон [Simon, 2011], проведя анализ деятельности четырех американских компаний - Amazon, Apple, Facebook и Google, делает вывод, что эти компании, по сути, стали первопроходцами в формировании новых моделей ведения бизнеса на основе цифровых платформ. Дж. Паркер и его коллеги [Паркер и др., 2017], обобщив успешный опыт многих платформенных компаний, сформировали и описали теоретические основы функционирования платформ.

В 2015 г. Центр глобального предпринимательства (The Center for Global Enterprise) начал проект формирования базы данных платформенных компаний всех регионов мира и секторов экономики. Однако в эту базу данных включены только компании с рыночной капитализацией более миллиарда долларов, тогда как на рынке, в том числе и российском, успешно работает множество платформенных компаний, не достигших таких объемов. Основные итоги анализа «эры платформ» по собранным данным представлены в работе Р. Эванс и А. Гувер [Evans, Gawer, 2016].

Различные аспекты функционирования платформ исследуют А. Гувер и М. Кусумано [Gawer, Cusumano, 2014], Д. Роджерс [Rogers, 2016], С. Чаудари [Choudary, 2015] и многие другие зарубежные авторы. Среди российских исследователей платформенных моделей бизнеса можно отметить следующие работы [Коваленко, 2016; Сооляттэ, 2011; Яблонский, 2013].

Однако, несмотря на рост числа публикаций по этой теме, вопросов пока остается больше, чем ответов, и создатели платформ являются первопроходцами в своей сфере, действуя методами проб и ошибок. В 2018 г. на российском рынке начали работу торговые платформы «Агро24», «Мир торговли» и «Яндекс.Маркет» с разныли бизнес-моделями, начинается тестовая эксплуатация платформы в сфере аренды спецтехники, идет 
работа над платформой сервиса автомобилей Сагсоіп, доска объявлений Avito объявила о планах преобразования в платформенную компанию, то есть началась «платформизация» российского бизнеса.

\section{Модель «продукт как услуга» (модель PaaS)}

Работая по модели «продукт как услуга», производитель владеет оборудованием и берет на себя его сопровождение и техническое обслуживание в обмен на регулярные платежи, причем клиенты платят по факту использования оборудования. Это стимулирует производителей выпускать более надежную, долговечную и простую в эксплуатации продукцию вместо ориентации на получение прибыли за счет продажи запасных частей и сервисных услуг, не предусмотренных гарантийными обязательствами.

Считается, что впервые такую модель поставок использовала компания Роллс-Ройс, которая предложила авиакомпаниям не покупать двигатели для самолетов, а оплачивать часы их налета (раньше авиаперевозчики платили при покупке фиксированную цену и дополнительно оплачивали обслуживание и ремонт). При такой модели производитель оборудования, в данном случае Роллс-Ройс, остается его собственником и обеспечивает сервисное обслуживание. Это требует существенных дополнительных расходов, но обеспечивает «привязку» потребителей и гарантированные регулярные платежи. Выгоды потребителя состоят в том, что он переводит инвестиции в операционные расходы, а также снимает с себя заботы об обслуживании и ремонте оборудования [Тапскотт, 2009]. На такую модель, в частности, планирует перейти компания «Аэрофлот».

Практическая реализация модели $\mathrm{PaS}$ стала возможна с развитием цифровых технологий, так как на оборудовании должны быть установлены датчики, постоянно передающие информацию о его работе. М. Портер и Дж. Хаппелманн отмечают, что если «раньше оборудование состояло из механических и электрических деталей, то теперь оно представляет собой сложные системы - с датчиками, памятью, микропроцессорами, программным обеспечением - обладающие коннективностью, то есть способностью взаимодействовать и обмениваться данными с другим оборудованием» [Портер, Хаппелманн, 2014. С. 50]. Эта «умная» 
техника заставляет переосмысливать многие процессы (такие как продажи и техническое обслуживание), предоставляя новые технологические возможности.

Вариантом модели «продукт как услуга» является совместное использование продукта (шеринг), например, автомобилей, которыми владеют каршеринговые компании.

Конкуренция на промышленных рынках, где западные компании представляют не только товары и технологии, но и новые формы продаж и обслуживания технически сложной продукции, вынуждает и российских производителей переходить на работу по модели «продукт как услуга», хотя этот процесс часто связан с немалыми финансовыми и организационными усилиями.

Так, ПАО «Криогенмаш», выпускающее установки по производству технических газов, предлагает потенциальным потребителям вместо оборудования покупать готовый газ on-site. Как написано на сайте компании, «при заключении долгосрочного договора на поставку технических газов Криогенмаш самостоятельно строит и эксплуатирует на площадке заказчика воздухоразделительное производство, способное обеспечить техническими газами основное производство». На время написания статьи число on-site проектов достигло восьми: это производство технических газов для Северского трубного, Первоуральского новотрубного, Таганрогского металлургического заводов и Ижорской промышленной площадки, «Томскнефтехима» и «Запсибнефтехима» (СИБУР), «Тулачермет-Стали» и «Уралхима».

Барнаульская компания «СиСорт», которая занимается разработкой и производством высокотехнологичного оборудования для сортировки сыпучих продуктов (фотосепараторов), поставляет их на европейский рынок по модели «продукт как услуга», так как потребители хотят получать услуги очистки, но не приобретать оборудование.

Заметим, что уже некоторые российские потребители оборудования задумываются о том, чтобы обновлять свои производственные мощности с опорой на такую модель. Единственная проблема связана с тем, что информация о загрузке оборудования, и, соответственно, об объемах выпуска, станет доступна «третьим лицам» (производителю оборудования). Обсуждая данную проблему, Портер и Хаппелманн указывают, что в договорах по модели «продукт как услуга» должны быть четко прописаны 
права на информацию (данные), которую передают датчики, установленные на оборудовании. По их мнению, скоро, вероятно, должна появиться четкая концепция права на интеллектуальную собственность такого рода [Портер, Хаппелманн, 2014. С. 67].

\section{Новая производственная (цифровая) философия}

В процессе цифровой трансформации бизнеса формируется новая производственная философия, основные контуры которой только прорисовываются, но связаны они с характерными чертами цифровой трансформации, такими как:

- умная (smart) автоматизация с выходом на принятие управленческих решений и развитие IЕМ-систем (интеллектуальных систем управления), которые приходят на смену ERP-системам;

- использование цифровых двойников процессов и объектов и создание «умной» продукции;

- развитие новых моделей бизнеса с ориентацией на партнерство и внешнюю связность;

- новые виды аналитики «больших данных»- предсказательная (Predictive) и предписывающая (Prescriptive) аналитика.

Новая производственная философия, в отличие от традиционной производственной или маркетинговой, акцентирует внимание на данных , которые становятся важным ресурсом компании, обеспечивая качественные изменения производства и сбыта продукции. «Данные наравне с людьми, технологиями, капиталом стали одним из основных активов корпораций, а часто и самым главным» [Портер, Хаппелманн, 2015. С. 77].

Работа с данными в компании предполагает организацию системы сбора информации с датчиков в рамках развития Интернета вещей, хранение структурированной и неструктурированной информации в разных форматах в концепции «озера данных», использование этих данных для моделирования и развития предписывающей аналитики с выходом на принятие управленческих решений.

Установлено, что любое промышленное предприятие генерирует огромный поток данных, особенно тех, которые характеризуют работу оборудования. Работа с этой информацией является одной из ключевых проблем Индустрии 4.0, или промышленного интернета, как принято называть это явление в России и США. 
До недавнего времени основной поток данных формировался на потребительских рынках, однако сейчас центр его генерации перемещается в производство. По мере развития цифровых технологий компании будут вынуждены действовать быстрее и умнее, повышать скорость обработки информации и принятия управленческих решений. Однако многие компании оказались неподготовленными к эре «больших данных», отмечает известный эксперт в сфере технологий Фил Саймон. Очень медленно компании приходят к пониманию, что для принятия обоснованных решений уже недостаточно традиционных инструментов типа Excel, KPI, стандартных отчетов и даже средств бизнес-аналитики. Эти инструменты не могут работать со все увеличивающимся потоком разнообразных типов информации [Simon, 2014].

С примерами использования алгоритмических принцииов извлечения знаний из «больших данных» и персонализации предложений сталкивается каждый человек, работающий с сервисами Google, Amazon, Alibaba, Сбербанк-онлайн и другими и получающий предложения и рекомендации, которые отвечают его интересам или потребностям. Перечисленные компании создали системы сбора и анализа информации, которые применительно к каждому клиенту отслеживают покупки и оценки товаров, частоту обращений к ссылкам, посещаемые сайты и другие сведения о его предпочтениях, алгоритмическая обработка которых позволяет в будущем точнее делать рекомендации. Это прескриптивная, предписывающая (Prescriptive) аналитика в действии.

В настоящее время быстрее всего на российских предприятиях, как и в других странах ${ }^{2}$, развивается сегмент предписывающей аналитики, связанной с ремонтно-профилактическими работами и техническим обслуживанием сложных изделий. Система предупреждает о потенциальных сбоях на самых ранних стадиях эксплуатации оборудования, указывая возможную причину их возникновения, представляя рекомендации по тому, что можно сделать, чтобы избежать сбоя или смягчить его последствия. Так, продукт под названием «виртуальный инженер» для работы с оборудованием и документацией на основе технологий виртуальной и дополненной реальности разработала новосибирская компания VRcorp.

${ }^{2}$ URL: http://mashportal.ru/company_news-44222.aspx - Январь 2017 г. (дата обращения: 10.03. 2018). 
Продукт предназначен для обучения сотрудников и технической поддержки выполнения сервисно-ремонтных и профилактических работ, основан на интерактивной системе справок.

Другим простым примером предсказательной аналитики является разработанный в крупнейшем отечественном агрохолдинге «Русагро» алгоритм управления процессом хранения свеклы. Основываясь на данных беспроводных датчиков температуры, влажности, углекислого газа в местах хранения свеклы и метеосводках и прогнозах погоды, система подает сигнал, из каких мест забирать сырье на переработку в первую очередь, этот сигнал получают технологи и функциональные руководители. Проект, по оценкам компании, окупился за год, позволив сократить потери сырья как минимум на $20 \%$. Для сбора информации в холдинге используют датчики, которыми оснащена вся техника (рядовые сотрудники пытались с ними бороться, но безуспешно), снимки из космоса; широко используются видеокамеры, дроны и другие методы сбора данных, которые хранятся и перерабатываются с использованием технологий Big Data. Над алгоритмами работают штатные математики и инженеры компании. Созданная в компании экспертная система выдает рекомендации по принятию решений: например, когда начинать посев на конкретном участке, какие семена использовать, сколько вносить удобрений и т.д. [Басов, 2017].

Компания «СИБУР» создала digital-подразделение 4 и сделала ряд шагов на пути цифровой трансформации бизнеса, в частности:

- на каждом предприятии установлена масса датчиков, которые в реальном времени отправляют данные о состоянии оборудования и технологического процесса (промышленный Интернет вещей);

- на основе Big Data разработаны алгоритмы-советчики, которые отслеживают потоковые данные и подсказывают оптимальный режим работы технологических установок. Такие алгоритмы работают на шести заводах в разных городах;

- в Томске запущен VR-тренажер (VR - virtual reality, виртуальная реальность) по ремонту компрессоров. Раньше, чтобы изучить компрессор изнутри, работники ждали его плановой остановки на ремонт. Теперь обучение идет намного быстрее;

${ }^{3}$ URL: rcorp.ru (дата обращения:10.03.2018).

${ }^{4}$ URL: https://sochi.hh.ru/article/312408 (дата обращения: 10.03.2018). 
VR- и AR-проекты заказали себе такие компании, как Сбербанк, «Росатом», «Газпром». Количество применений и разработок в этой сфере непрерывно увеличивается.

Мы привели лишь небольшое количество примеров цифровой трансформации бизнеса, которые активно идут на российских предприятиях. В первую очередь эти процессы охватывают деятельность по сервисному обслуживанию оборудования, отработке навыков рабочих, но постепенно меняются и управленческие принципы и подходы. Развиваются равноправное партнерство и совместное использование ресурсов, двигаясь в сторону блокчейна и открытости бизнеса; реализуется принцип предоставления товаров и услуг «по требованию» (модель «продукт как услуга») с гибкой формой оплаты по реальному потреблению; в условиях видимости данных и процессов транзакций происходит персонализация отношений с клиентами и партнерами и формирование сообществ; развивается предписывающая аналитика и алгоритмизация процессов управления.

Естественно, что темп вытеснения старого (старых технологий, моделей бизнеса, принципов управления и т.д.) новым зависит от соотношения двух сил: насколько быстро созреет система новшеств и насколько живучей окажется старая система. Соответственно, сложности процессов цифровой трансформации определяются не только технологическими факторами, но и методическими, организационными, а главное - ментальными проблемами. Такие проблемы есть как у сотрудников, которые, например, пытаются выводить из строя датчики расходов топлива, так и у менеджеров, которые недооценивают роль данных как нового актива компаний.

Портер и Хаппелманн считают, что поскольку масштаб изменений при цифровой трансформации огромен, а знаний и опыта в этой сфере не хватает, многие компании будут создавать гибридные или переходные организации, выделяя отдельные подразделения, которые занимаются цифровой трансформацией, что позволит им собрать в одном месте лучших специалистов, избежать дублирования работ, освоить нужные знания и навыки [Портер, Хаппелманн, 2015. С. 92]. Так, компания General Electric, начиная цифровую трансформацию бизнеса, собрала около 20 тыс. программистов, которые работали в ее структурах и стартапах, 
в одном месте, что позволило ей довольно быстро начать работать по модели $\mathrm{PaaS}$, создать цифровую платформу Predix для промышленного Интернета, которую она продвигает в России, и занять лидирующие позиции на своих промышленных рынках.

При этом компании, занявшие выжидательную позицию, рискуют потерпеть поражение, поскольку их конкуренты, которые начнут цифровую трансформацию раньше, опираясь на многочисленные данные, смогут быстро вырваться вперед, и за ними будет сложно угнаться [Уэссел и др., 2017. С. 63]. Пока ещзе отставание некритично, все в начале пути, но надо смотреть вперед и готовиться. Начинать надо с данных (собирать их, анализировать) и с обучения специалистов. В заключение отметим, что цифровая трансформация российского бизнеса постепенно набирает обороты, но лишь время покажет, кто успел, а кто отстал навсегда.

\section{Литература}

Басов М. Глава «Русагро» о том, как сельское хозяйство превращается в цифровой бизнес //Harvard Business Review - Россия. 2017. Май. С. 26-29.

Грингард С. Интернет вещей. Будущее уже здесь. М.: Альпина Паблишер, 2016.

Иансати М., Лакхани К. Вездесущая «цифра» // Harvard Business Review Россия. 2014. Декабрь. С. 73-83.

Коваленко А.И. Проблематика исследований многосторонних платформ // Современная конкуренция. 2016. Т. 10. № 3 (57). С. 64-90.

Кузнецова С.А., Маркова В. Д. Проблемы формирования бизнес-экосистемы на основе цифровой платформы: на примере платформы компании $1 \mathrm{C} / /$ Инновации. 2018, № 2. С. 52-57.

Купер Р. Дж. Седьмое чувство. Под знаком предсказуемости: как прогнозировать и управлять изменениями в цифровую эпоху. М.: Эксмо, 2017.

Маркова В.Д. Цифровая экономика. М.: Инфра-М, 2018.

Паркер Дж. Революция платформ. Как сетевые рынки меняют экономикукак заставить их работать на вас / Дж. Паркер, М. Альстин, С. Чаудари; [пер. с англ.] М.: Манн, Иванов и Фербер, 2017.

Портер М., Хаппелманн Дж. Революция в конкуренции. «Умные» технологии изменяют конкурентную борьбу // Harvard Business Review - Россия. 2014. Декабрь. С. 49-71.

Портер М., Хаппелманн Дж. Революция в производстве: «умные» технологии перекраивают компании // Harvard Business Review - Россия, 2015. Ноябрь. С. 74-93.

Сооляттэ A. Бизнес-модели на основе многосторонних платформ - инновации, революционно преобразующие бизнес, 2011 [Эл. pecypc]. URL: https:// www.e-xecutive.ru/community/magazine/1509147-andrei-soolyatte-biznes-modelina-osnove-mnogostoronnih-platform-innovatsii-revolutsionno-preobrazuuschie-biznes 
Тапскотт Д., Уильямс Э.Д. Викиномика. Как массовое сотрудничество изменяет все. СПб.: Бест Бизнес Букс, 2009.

Уэссел М., Леви Э., Сигел Р. Рывок в цифровую экономику // Harvard Business Review - Россия. 2017. Март. С. 59-65.

Яблонский С. А. Многосторонние платформы и рынки: основные подходы, концепции и практики // Российский журнал менеджмента. 2013. № 4. С. 57-78.

Choudary S. P. Platform Scale: How an emerging business model helps startups build large empires with minimum investment. Platform Thinking Labs, 2015.

Eisenmann T. Opening platforms: how, when and why? - Boston: Harvard Business School, 2008.

Evans $P$. and Gawer A. The Rise of the Platform Enterprise. Global Survey. The Emerging Platform Economy series. 2016. Jan.

Gawer A. and Cusumano M. Industry Platforms and Ecosystem Innovation // J. Prod. Innov. Management. 2014. № 31 (3). Pp. 417-433.

Muegge S. Platforms, communities and business ecosystems: lessons learned about technology entrepreneurship in an interconnected world // Technology Innovation Management Review. 2013. February. Pp. 5-15.

Rogers D. The Digital Transformation Playbook: Rethink Your Business for the Digital Age. Columbia Business School Publishing, 2016.

Simon Phil. The Age of the Platform: How Amazon, Apple, Facebook, and Google Have Redefined Business. Paperback, 2011.

Simon Phil. The Visual Organization: Data Visualization, Big Data, and the Quest for Better Decisions. Hardcover, 2014.

Zhu F. and Iansiti M. Entry into platform-based markets // Strategic Management Journal. 2012. № 33 (1). Pp. 88-106.

Статья поступила 18.07.2018.

\section{Summary}

Markova V.D., Institute of Economics and Industrial Engineering, SB RAS, Novosibirsk

\section{Influence of Digital Economy on Business}

Author's position concerning directions of digital economy's influence on industrial companies' activities is presented in the paper. Russian and foreign publications on digital transformation practices are analyzed. Main attention is paid to new instruments and principles of business management which determine company's competitiveness in digital economy and help to develop new production philosophy. Analysis of Russian companies' cases revealed that digital transformation yet covers only limited number of processes and business objects.

Digital transformation of business; platform business models, model «product as a service»; new production philosophy

\section{References}

Basov M. (2017). Glava "Rusagro" o tom, kak sel'skoe hozjajstvo prevrashhaetsja v cifrovoj biznes. Harvard Business Review - Russia, May. Pp. 26-29. (In Russ.).

Greengard S. (2016). The Internet of Things. Moscow. Al'pina Pabl., 188 p. (In Russ.). 
Iansiti M., Lakhani K. (2014). Vezdesushhaja “cifra”. Harvard Business ReviewRussia, Dec. Pp. 73-83. (In Russ.).

Kovalenko A.I. (2016). Problematika issledovanij mnogostoronnih platform. Journal of Modern Competition. Vol. 10. No. 3. Pp. 64-90. (In Russ.).

Kuznetsova S.A., Markova V.D. (2018). Problemy formirovanija biznesjekosistemy na osnove cifrovoj platformy: na primere platformy kompanii 1C. Innovatsii [Innovation]. No. 10. Pp. 52-57. (In Russ.).

Cooper R. J. (2017). The Seventh Sense. Moscow Publ., 336 p. (In Russ).

Markova V.D. (2018). Cifrovaja ekonomika. Moscow Publ., 186 p. (In Russ).

Parker G., Alstain M., Choudary S. (2017). Platform revolution. Moscow. Mann, Ivanov, Farber Publ., 304 p. (In Russ.).

Porter M., Happelmann J. (2014). Revoljucija v konkurencii. «Umnye» tehnologii izmenjajut konkurentnuju bor'bu. Harvard Business Review - Russia, Dec. Pp. 49-71. (In Russ.).

Porter M., Happelmann J. (2015). Revoljucija v proizvodstve: «umnye» tehnologii perekraivajut kompanii. Harvard Business Review - Russia, Nov. Pp. 74-93. (In Russ.).

Sooljattje A. (2011). Biznes-modeli na osnove mnogostoronnih platform innovacii, revoljucionno preobrazujushhie biznes, Available at: https://www.e-xecutive. $\mathrm{ru} /$ community/magazine/1509147-andrei-soolyatte-biznes-modeli-na-osnovemnogostoronnih-platform-innovatsii-revolutsionno-preobrazuuschie-biznes

Tapscott D., Williams A. (2009). Wikinomics. How mass collaboration changes everything. St. Petersburg: Best Business Books Publ., 388 p. (In Russ.).

Wessel M., Levie A., Siegel R. (2017). Ryvok v cifrovuju ekonomiku. Harvard Business Review - Russia. Mar. Pp. 59-65. (In Russ.).

Jablonskij S.A. (2013) Mnogostoronnie platformy i rynki: osnovnye podhody, koncepcii i praktiki. Rossijskij zhurnal menedzhmenta [Russian Management Journal]. No. 4. Pp. 57-78. (In Russ.).

Choudary S.P. (2015). Platform Scale: How an emerging business model helps startups build large empires with minimum investment. Platform Thinking Labs, 2015.

Eisenmann T. (2008). Opening platforms: how, when and why? Boston: Harvard Business School.

Evans P., Gawer A. (2016). The Rise of the Platform Enterprise. Global Survey. The Emerging Platform Economy series. Jan.

Gawer A., Cusumano M. (2014). Industry Platforms and Ecosystem Innovation. J. Prod. Innov. Managementю. No. 31 (3). Pp. 417-433.

Muegge S. (2013). Platforms, communities and business ecosystems: lessons learned about technology entrepreneurship in an interconnected world. Technology Innovation Management Review. February. Pp. 5-15.

Rogers D. (2016). The Digital Transformation Playbook: Rethink Your Business for the Digital Age. Columbia Business School Publishing.

Simon Phil (2011). The Age of the Platform: How Amazon, Apple, Facebook, and Google Have Redefined Business. Paperback.

Simon Phil (2014). The Visual Organization: Data Visualization, Big Data, and the Quest for Better Decisions. Hardcover.

Zhu F., Iansiti M. (2012). Entry into platform-based markets. Strategic Management Journal. No. 3 (1). Pp. 8-106. 